Original article

\title{
Glucose-6-phosphate dehydrogenase-derived NADPH fuels superoxide production in the failing heart
}

\author{
Sachin A. Gupte ${ }^{a, *}$, Robert J. Levine ${ }^{\text {a }}$, Rakhee S. Gupte ${ }^{\text {a }}$, Martin E. Young ${ }^{\text {b }}$, \\ Vincenzo Lionetti ${ }^{\text {a,c }}$, Volodymyr Labinskyy ${ }^{\text {a,c }}$, Beverly C. Floyd ${ }^{a}$, Caroline Ojaimi ${ }^{\text {a }}$, \\ Michelle Bellomo ${ }^{\text {a }}$, Michael S. Wolin ${ }^{\text {a }}$, Fabio A. Recchia ${ }^{\text {a,c }}$ \\ a Department of Physiology, BSB Room 626, New York Medical College, Valhalla, NY 10595, USA \\ ${ }^{\mathrm{b}}$ USDA/ARS Children's Nutrition Research Center, Baylor College of Medicine, Houston, TX, USA \\ ${ }^{c}$ Sector of Medicine, Scuola Superiore S. Anna, Pisa, Italy
}

Received 18 February 2006; received in revised form 1 May 2006; accepted 5 May 2006

\begin{abstract}
In the failing heart, NADPH oxidase and uncoupled NO synthase utilize cytosolic NADPH to form superoxide. NADPH is supplied principally by the pentose phosphate pathway, whose rate-limiting enzyme is glucose 6-phosphate dehydrogenase (G6PD). Therefore, we hypothesized that cardiac G6PD activation drives part of the excessive superoxide production implicated in the pathogenesis of heart failure. Pacing-induced heart failure was performed in eight chronically instrumented dogs. Seven normal dogs served as control. End-stage failure occurred after $28 \pm 1$ days of pacing, when left ventricular end-diastolic pressure reached $25 \mathrm{~mm} \mathrm{Hg}$. In left ventricular tissue homogenates, spontaneous superoxide generation measured by lucigenin $(5 \mu \mathrm{M})$ chemiluminescence was markedly increased in heart failure $(1338 \pm 419 \mathrm{vs} .419 \pm 102 \mathrm{AU} / \mathrm{mg}$ protein, $P<0.05)$, as were NADPH levels $(15.4 \pm 1.5 \mathrm{vs} .7 .5 \pm 1.5 \mu \mathrm{mol} / \mathrm{gww}, P<0.05)$. Superoxide production was further stimulated by the addition of NADPH. The NADPH oxidase inhibitor gp91 ${ }^{\text {ds-tat }}(50 \mu \mathrm{M})$ and the NO synthase inhibitor L-NAME $(1 \mathrm{mM})$ both significantly lowered superoxide generation in failing heart homogenates by $80 \%$ and $76 \%$, respectively. G6PD was upregulated and its activity higher in heart failure compared to control $(0.61 \pm 0.10$ vs. $0.24 \pm 0.03 \mathrm{nmol} / \mathrm{min} / \mathrm{mg}$ protein, $P<0.05)$, while superoxide production decreased to normal levels in the presence of the G6PD inhibitor 6-aminonicotinamide. We conclude that the activation of myocardial G6PD is a novel mechanism that enhances NADPH availability and fuels superoxide-generating enzymes in heart failure.
\end{abstract}

(C) 2006 Elsevier Inc. All rights reserved.

Keywords: Heart failure; NADPH oxidase; Glucose-6-phosphate; Pentose phosphate pathway

\section{Introduction}

Excessive production of reactive oxygen species (ROS) is implicated in the pathogenesis of several cardiovascular diseases, including heart failure [1]. A large number of clinical and experimental studies have shown increased oxidative stress in the failing heart, with detrimental consequences that range from endothelial dysfunction to contractile impairment and ventricular remodeling [2]. The main sources of superoxide anion $\left(\mathrm{O}_{2}^{-}\right)$, a major precursor of reactive oxygen species,

\footnotetext{
* Corresponding author. Fax: +1 9145944018.

E-mail address: sachin_gupte@nymc.edu (S.A. Gupte).
}

include the mitochondrial respiratory chain [3], xanthine oxidase [4], and NADPH oxidase [5]. The relative contribution of these enzymes to $\mathrm{O}_{2}^{-}$production in the failing heart is not well defined, yet. Recent studies have suggested important roles for both xanthine oxidase [6], and NADPH oxidase as sources of cardiac $\mathrm{O}_{2}^{-}$in heart failure patients $[7,8]$. The latter enzyme utilizes both cytosolic NADPH or NADH as donors of reducing equivalents to transfer one electron to molecular oxygen, thereby producing $\mathrm{O}_{2}^{-}$. The increased activity of NADPH oxidase in response to mediators such as angiotensin II, norepinephrine, and $\mathrm{TNF} \alpha$ is presently recognized as a chief mechanism of vascular disease [9], but its potential impact on oxidative stress of the failing myocardium requires further elucidation. In addition, when constitutive NO synthase is 
uncoupled from essential cofactors, as found in the failing heart, it transfers electrons from NADPH to oxygen, thus becoming an additional source of $\mathrm{O}_{2}^{-}$[10].

The generation of $\mathrm{O}_{2}^{-}$from NADPH oxidase and uncoupled NO synthase depends not only on enzyme activation, but also on the availability of reducing equivalents. It is conceivable, therefore, that, in the presence of hyperactive NADPH oxidase and uncoupled NO synthase, alterations of the metabolic pathways accounting for $\mathrm{NAD}^{+}$and $\mathrm{NADP}^{+}$reduction can potentially affect the rate of $\mathrm{O}_{2}^{-}$production. Other investigators and we have previously reported profound alterations of fatty acid and carbohydrate metabolism in the failing heart [11]. In particular, myocardial glucose uptake and oxidation are increased [12,13], although the glycolytic pathway and the mitochondrial capacity to oxidize carbohydrates appear downregulated, as opposed to upregulated [14,15]. A small fraction of total glucose in the cytosol can also be oxidized to ribose by the pentose phosphate pathway. Moreover, it has been previously shown by us and others that NADPH oxidase preferentially utilizes NADPH derived from the pentose phosphate pathway $[16,17]$. In the light of these findings, we hypothesized that, in the failing heart, more glucose is oxidized through the pentose phosphate pathway, with a consequent increase in electron donors available to fuel $\mathrm{O}_{2}^{-}$generating enzymes. This hypothesis was tested in myocardial tissue harvested from dogs with pacing-induced heart failure, an established model of dilated cardiomyopathy.

\section{Methods}

\subsection{Surgical instrumentation and in vivo protocol}

Fifteen dogs were chronically instrumented and heart failure was induced in eight by pacing the left ventricle at 210 beats/min for 3 weeks and at 240 beats/min thereafter. The remaining seven dogs were used as a control. Hemodynamics recordings and two-dimensional and M-mode echocardiography were performed at baseline and during terminal decompensation. Dogs were considered in end-stage heart failure when left ventricular end-diastolic pressure reached $25 \mathrm{~mm} \mathrm{Hg}$ and clinical signs of severe decompensation were observed. At this point, the dogs were anesthetized with $30 \mathrm{mg} / \mathrm{kg}$ i.v. of sodium pentobarbital to harvest and snapfreeze left ventricular tissue samples. These methods have been fully described by us [18] and the protocol was approved by the Institutional Animal Care and Use Committee of the New York Medical College.

\subsection{Cardiac tissue}

Left ventricular tissue was pulverized in liquid nitrogen and homogenates were prepared in MOPS $(50 \mathrm{mmol} / \mathrm{l})$-Sucrose ( $250 \mathrm{mmol} / \mathrm{l})$ buffer at $\mathrm{pH} 7.4$, as previously described $[17,19]$. Only freshly prepared homogenates were used for biochemical assays.

To identify the source of $\mathrm{O}_{2}^{-}$, the homogenates were brought to a final volume of $50 \mu \mathrm{l}$ and pretreated for $30 \mathrm{~min}$ with: (1) the xanthine oxidase inhibitors allopurinol $(100 \mu \mathrm{mol} / \mathrm{l})[20]$ and oxypurinol (100 $\mu \mathrm{mol} / 1)$ [21]; (2) the cofactor tetrahydrobiopterin $(10 \mu \mathrm{mol} / \mathrm{l})$ [22], and the inhibitor L-NAME (1 mmol/l) [10] to prevent $\mathrm{O}_{2}^{-}$generation from $\mathrm{NO}$ synthase; (3) the specific NADPH oxidase inhibitor gp91 ${ }^{\text {ds-tat }}(50 \mu \mathrm{mol} / \mathrm{l})$ [23]; (4) 6-aminonicotinamide ( $5 \mathrm{mmol} / \mathrm{l})$, an inhibitor of glucose-6phosphate dehydrogenase [17,24]. Time-matched control samples were incubated for 30 minutes at $37^{\circ} \mathrm{C}$ without adding any drug. Incubated samples $(20 \mu \mathrm{l})$ were placed in plastic scintillation minivials containing $5 \mu \mathrm{M}$ lucigenin for the detection of $\mathrm{O}_{2}^{-}$in a final volume of $1 \mathrm{ml}$ of air-equilibrated Krebs solution buffered with $10 \mathrm{mmol} / \mathrm{l}$ HEPES-NaOH $(\mathrm{pH}$ 7.4), as previously described [17]. In a separate set of experiments, lucigenin chemiluminescence was measured from normal and heart failure homogenate samples without and with NADPH $(50-\mu \mathrm{mol} / 1)$. Lucigenin assays were done in the presence and absence of $\mathrm{O}_{2}^{-}$scavenger, superoxide dismutase (SOD).

\subsection{Hydrogen peroxide and peroxynitrite production}

Hydrogen peroxide levels were measured by chemiluminescence methods as previously described [25]. Briefly, hydrogen peroxide was estimated by incubating homogenate samples $(10 \mu \mathrm{l})$ in luminol $(10 \mu \mathrm{mol} / \mathrm{l})$ and horseradish peroxidase $(100 \mathrm{nmol} / \mathrm{l})$ with and without catalase $(200 \mathrm{U} / \mathrm{ml})$, and luminol chemiluminescence was measured. To measure peroxynitrite production, tissue homogenate samples $(10 \mu 1)$ were incubated in luminol $(100 \mu \mathrm{mol} / \mathrm{l})$ and luminol chemiluminesence was used after a brief modification as previously described [26]. Luminol assays were done in the presence and absence of $\mathrm{H}_{2} \mathrm{O}_{2}$ scavenger, catalase.

\subsection{Glutathione concentration and glutathione reductase activity}

Frozen samples were homogenized in $50 \mathrm{mmol} / 1$ potassium phosphate buffer, $\mathrm{pH}$ 6-7, $1 \mathrm{mmol} / \mathrm{l}$ EDTA and then centrifuged at $10,000 \times g$ for $15 \mathrm{~min}$ at $4{ }^{\circ} \mathrm{C}$. The supernatant was used for measurement of oxidized glutathione (GSSG) after deproteinating the sample with equal amounts of $5 \mathrm{~g} / 50 \mathrm{ml}$ metaphosphoric acid. The samples were centrifuged at $2000 \times g$ for at least $2 \mathrm{~min}$, and the supernatant was used for GSSG measurement after neutralization with $4 \mathrm{~mol} / \mathrm{l}$ triethanolamine. After separation by centrifugation and neutralization, the samples were treated with $1 \mathrm{~mol} / 1$ 2-vinylpyridine. GSSG concentration was measured using a commercially available assay kit (Cayman Chemical) [27]. Also, glutathione reductase activity in myocardial homogenates was determined by a commercially available kit (Cayman Chemical).

\subsection{Superoxide dismutase activity}

We measured superoxide dismutase (SOD) activity as an indicator of oxidative stress induced by $\mathrm{O}_{2}^{-}$[28]. Cardiac tissue homogenates was assayed with a commercially available kit (Cayman Chemicals). 


\subsection{Lipid peroxidation}

Malondialdehyde and 4-hydroxyalkenals, end products of peroxidation of polyunsaturated fatty acids with related esters, were measured in cardiac tissue extract with a colorimetric method by employing a commercially available assay kit (Calbiochem) [18].

\subsection{Oxidized and reduced pyridine nucleotide concentrations}

NADPH was determined by HPLC using previously described methods [17]. Briefly, to measure NADPH, frozen tissues were homogenized in an extraction medium containing $\mathrm{NaOH}(0.02 \mathrm{~N})$ and cysteine $(0.5 \mathrm{mmol} / \mathrm{l})$ at $0{ }^{\circ} \mathrm{C}$. The extracts then were heated at $60{ }^{\circ} \mathrm{C}$ for $10 \mathrm{~min}$ and neutralized with $2 \mathrm{ml}$ of $0.25 \mathrm{M}$ glycylglycine buffer, $\mathrm{pH}$ 7.6. The neutralized extracts were centrifuged at $10,000 \times g$ for $10 \mathrm{~min}$, the supernatants were passed through $0.45 \mu \mathrm{m}$ Millipore filters, and the filtered solutions were used to measure NADPH by HPLC. NADPH were eluted from a reverse-phase HPLC column $\left(4.6 \times 250 \mathrm{~mm}\right.$; Supelco $\mathrm{C}_{18}$, Sigma $)$ at room temperature using HP 1100 Series (Agilent Technologies, DE) with a buffer system consisting of $100 \mathrm{mmol} / \mathrm{l}$ potassium phosphate (pH 6.0) (buffer A), and $100 \mathrm{mmol} / \mathrm{l}$ potassium phosphate ( $\mathrm{pH}$ 6.0) containing 5\% methanol (buffer B). The column was eluted with $100 \%$ buffer $A$ from 0 to $8.5 \mathrm{~min}, 80 \%$ buffer $A$ plus $20 \%$ buffer $B$ from 8.5 to $14.5 \mathrm{~min}$, and $100 \%$ buffer $B$ from 14.5 to $40 \mathrm{~min}$. The flow rate was $1.0 \mathrm{ml} / \mathrm{min}$, and the ultraviolet absorbance was monitored at $260 \mathrm{~nm}$. NADPH standards were used to calibrate the HPLC. Internal standards containing $2 \mathrm{nmol}$ of NADPH, NADH, NADP ${ }^{+}$, and $\mathrm{NAD}^{+}$were used to verify the quantitative recovery of the extraction procedure and HPLC retention time in the presence and absence of tissue samples.

\subsection{Glucose-6-phosphate dehydrogenase activity}

The activity glucose-6-phosphate dehydrogenase (G6PD), the rate limiting enzyme in the pentose phosphate pathway, was measured in myocardial tissue homogenates by following the reduction of $\mathrm{NADP}^{+}$to NADPH [17]. NADPH fluorescence was detected at $340 \mathrm{~nm}(\mathrm{Ex})$ and $460 \mathrm{~nm}$ (Em) using a Flx800 microplate fluorescence detector, BioTek Instruments, Winooski, Vermont, USA.

\subsection{6-Phosphogluconate concentration}

6-Phosphogluconate, a product of the oxidative branch of the pentose phosphate pathway, was measured in myocardial tissue by the method of Kauffman et al. [29]. The reduction of NADP ${ }^{+}$ (0.02 $\mathrm{mmol} / \mathrm{l})$ to NADPH was catalyzed by 6-phosphogluconate dehydrogenase $(0.5 \mu \mathrm{g} / \mathrm{ml})$ at $37^{\circ} \mathrm{C}$ for $20 \mathrm{~min}$ in Tris- $\mathrm{HCl}$ (0.05 mol/l) buffer ( $\mathrm{pH} 8.0)$ containing EDTA $(0.1 \mathrm{mmol} / \mathrm{l})$, dithiothreitol $(0.1 \mathrm{mmol} / \mathrm{l})$, and ammonium acetate $(0.03 \mathrm{~mol} / \mathrm{l})$. NADPH concentration was then detected fluorometrically as previously described by us [17].

\subsection{Real-time polymerase chain reaction}

The expression of selected genes was quantitated by realtime quantitative polymerase chain reaction (PCR) as described previously [18]. Analysis was focused on G6PD and the NADPH subunits Nox-2 and Nox-4, while the traditional housekeeping gene ribosomal $18 \mathrm{~S}$ was used for normalization. We chose to measure Nox-4 and Nox-2 expression, since both these oxidases are expressed in vascular and myocardial tissue $[7,17]$. Specific quantitative assays were designed from dog sequences available in GenBank, except in the cases of Nox-2 and Nox-4 for which the dog sequences were not available. In contrast, these genes have been cloned for the human, mouse, and rat. Multiple assays were then designed using the human sequence for these genes, in a region that was highly conserved between the three species. These human-specific assays were subsequently tested for compatibility in the dog. Primers and probes were designed to be isoform specific, spanning sites where two exons join (splice sites) when such sites are known (preventing recognition of the assay to any potential contaminating genomic DNA). Sequences of these primers and probes are given in Table 1. Standard RNA was made for all assays by the T7 polymerase method (Ambion), using total RNA isolated from the dog heart. Transcript levels are expressed as the number of molecules of mRNA per nanogram of total RNA (as measured by UV spectrophotometry).

\subsection{Western immunoblot analysis}

Protein was extracted from frozen tissue as previously described [17] and its concentration measured spectrophotometrically with a colorimetric assay (Bio-Rad DC reagent).

Table 1

Primer and probe sequences used in real time quantitative RT-PCR

\begin{tabular}{|c|c|c|}
\hline Gene & Primer/Probe & Sequence \\
\hline \multirow[t]{3}{*}{ g6pd } & Forward & 5'-GACCACTACCTGGGCAAGG-3' \\
\hline & Reverse & 5'-CGATGTTGTCTCGGTTCCA-3' \\
\hline & Probe & 5'-FAM-ATCCTGTTGGCAAACCTCAGCACCAT-TAMRA-3' \\
\hline \multirow[t]{3}{*}{ nox 2} & Forward & 5'-AGCCAGATGCAGGAAAGGA-3' \\
\hline & Reverse & 5'-TCATCATGGTGCACAGCAAA-3' \\
\hline & Probe & 5'-FAM-ATTGGCCTGAGACTCATCCCAGCCA-TAMRA-3' \\
\hline \multirow[t]{3}{*}{ nox4 } & Forward & 5'-CGTCCTCGGTGGAAACTTTT-3' \\
\hline & Reverse & 5'-GTGAATTGGGTCCACAACAGA-3' \\
\hline & Probe & 5'-FAM-CACCAACTGTTTTTCCTCTGTTATATTTTGCTATTTCA-TAMRA-3' \\
\hline
\end{tabular}


Thirty-five micrograms of total protein was separated by electrophoresis, transferred onto a PVDF membrane, and incubated with specific antibody against G6PD (1:500 dilution, Sigma Chemical), Nox-2 (1:100 dilution, Transduction Laboratory), and Nox-4 (1:100 dilution, Santacruz Biotechnology). After conjugation with the secondary antibody, the membranes were developed in a chemiluminescence substrate solution (Pierce SuperSignal Chemiluminescence Substrate), and re-probed for calsequestrin [14] to verify the uniformity of protein loading. Bands were visualized by autoradiography and quantified using commercially available software. Results are expressed as percentage of the density of a standard sample loaded on all membranes in triplicate.

\subsection{Coimmunoprecipitation}

The activation state of NADPH oxidase was tested by determining the formation of complexes of Nox bound to the recruitable subunits of the enzyme [30]. Therefore, we first tested commercially available antibodies to detect the subunits $\mathrm{p} 47^{\text {phox }}, \mathrm{p} 67^{\text {phox }}$, and rac-1 in canine tissue. Unfortunately, we obtained a good and reproducible signal only with the antip $67^{\text {phox }}$ antibody. Frozen samples were homogenized in $20 \mathrm{mM}$ Tris- $\mathrm{HCl}$ pH 7.4 buffer, containing 1\% NP-40, $0.25 \%$ sodium deoxycholate, $100 \mathrm{mM} \mathrm{NaCl}, 1 \mathrm{mM}$ EGTA, $1 \mathrm{mM}$ PMSF, $1 \mathrm{mM} \mathrm{Na} \mathrm{VO}_{4}, 1 \mathrm{mM} \mathrm{NaF}, 1 \mu \mathrm{g} / \mathrm{ml}$ aprotinin, $1 \mu \mathrm{g} / \mathrm{ml}$ leupeptin, and $1 \mu \mathrm{g} / \mathrm{ml}$ pepstatin. After protein extraction, $\mathrm{p} 67^{\text {phox }}$ was immunoprecipitated using goat polyclonal antibodies (Santa Cruz Biotechnology, Santa Cruz, CA, USA) bound to IgA and IgG beads (Santa Cruz Biotechnology, Santa Cruz, CA, USA), after which SDS gel electrophoresis will be performed. Separated proteins were blotted onto $0.2 \mu \mathrm{m}$ nitrocellulose $(16 \mathrm{~h}, 30 \mathrm{~V})$ and immunostained with anti-Nox-2 antibody (BD Bioscience, San Diego, CA, USA) followed by incubation with HRPlabeled appropriate secondary antibodies (Pierce, IL, USA). Specific proteins were detected by chemiluminescence (Pierce).

\subsection{Statistical analysis}

Values are expressed as means \pm SEM. Differences among groups were tested with one-way ANOVA followed by Bonferroni's post hoc test. The acceptable level of significance was $P<0.05$. Differences were considered statistically significant at a nominal significance of $P<$ 0.05 .

\section{Results}

\subsection{Heart failure}

Dogs developed end-stage failure after $28 \pm 1$ days of pacing, when left ventricular end-diastolic pressure reached $25 \mathrm{~mm} \mathrm{Hg}$. Changes in the main hemodynamic and echocardiographic parameters are summarized in Table 2 .
Table 2

Hemodynamics and echocardiographic parameters at control and in end-stage heart failure

\begin{tabular}{lcc}
\hline & Control $(n=7)$ & Heart failure $(n=8)$ \\
\hline LVEDP (mm Hg) & $6 \pm 1.0$ & $25 \pm 1.5^{*}$ \\
LVSP (mm Hg) & $127 \pm 3.3$ & $96 \pm 2.8^{*}$ \\
$\mathrm{~d} P / \mathrm{d} t_{\text {max }}\left(\mathrm{mm} \mathrm{Hg} \mathrm{s}^{-1}\right)$ & $3048 \pm 200$ & $1372 \pm 100^{*}$ \\
MCBF $\left(\mathrm{ml} \mathrm{min}^{-1}\right)$ & $34.9 \pm 3.9$ & $30.2 \pm 4.7$ \\
LVEDD $(\mathrm{mm})$ & $44.3 \pm 1.0$ & $52.0 \pm 1.5^{*}$ \\
LVEF $(\%)$ & $69 \pm 3.6$ & $31.4 \pm 2 *$
\end{tabular}

LVEDP, left ventricular end-diastolic pressure; LVSP, left ventricular systolic pressure; $\mathrm{d} P / \mathrm{d} t_{\max }$, maximum derivative of left ventricular pressure; MCBF, mean blood flow in the left circumflex coronary artery; LVEDD, left ventricular end-diastolic diameter; LVEF, left ventricular ejection fraction.

* $P<0.05$ vs. control.

\subsection{Superoxide production, superoxide dismutase activity, hydrogen peroxide generation, and products of lipid peroxidation}

Fig. 1 shows $\mathrm{O}_{2}^{-}$levels in myocardial tissue from normal (1A) and failing (1B) hearts detected by lucigenin $(5-\mu \mathrm{mol} / \mathrm{l})$ chemiluminescence. $\mathrm{O}_{2}^{-}$was significantly higher in failing myocardium. In few experiments, $\mathrm{O}_{2}^{-}$detections were performed in the absence and presence of NADPH regenerating system consisting of glucose-6-phosphate $(200 \mu \mathrm{mol} / \mathrm{l})$ and $\mathrm{NADP}^{+}(100 \mu \mathrm{mol} / \mathrm{l})$ added in each reaction. Addition of NADPH regenerating system to each reaction did affect basal $\mathrm{O}_{2}^{-}$generation. Pretreatment of normal $(n=7)$ and heart failure $(n=8)$ myocardial tissue with polyethylene glycol-superoxide dismutase $(500 \mathrm{U} / \mathrm{ml})$ and tiron $(10 \mu \mathrm{M})$ inhibited lucigenin chemiluminescence, indicating that the signal was specific for $\mathrm{O}_{2}^{-}$. No pharmacological agents used in this study, except for tetrahydrobiopterin and gp91 ${ }^{\mathrm{ds}-\text { tat }}$, attenuated $\mathrm{O}_{2}^{-}$signals in normal myocardium (Fig. 1A). In failing myocardium (Fig. $1 \mathrm{~B})$, the $\mathrm{O}_{2}^{-}$-induced chemiluminescence was not significantly changed by the xanthine oxidase inhibitors, allopurinol and oxypurinol, but was attenuated $(P<0.05)$ by the NO synthase cofactor tetrahydrobiopterin and inhibitor L-NAME $(50-60 \%)$, and by the NADPH oxidase inhibitor gp91 $1^{\text {ds-tat }}$ $(80-90 \%)$. A scrambled analogue of gp91 ${ }^{\text {ds-tat }}$ did not exert any effect on $\mathrm{O}_{2}^{-}$and $\mathrm{H}_{2} \mathrm{O}_{2}$ production in normal and heart failure myocardial homogenates.

Furthermore, we measured SOD activity as an indirect indicator of oxidative stress [28] induced by elevated $\mathrm{O}_{2}^{-}$levels in normal and heart failure myocardial homogenates. As shown in Fig. 1C, SOD activity was significantly higher in heart failure. Consistent with these results, we also found that $\mathrm{H}_{2} \mathrm{O}_{2}$ generation increased in heart failure compared to control (Fig. 1D). Furthermore, peroxynitrite production in cardiac tissue homogenates was not significantly different in heart failure compared to control $(707 \pm 228$ vs. $1200 \pm 408$ arbitrary units/ mg protein).

Finally, the myocardial lipid peroxidation end products malondialdehyde and 4-hydroxyalkenals were higher in heart failure compared to control $(7.9 \pm 0.97$ vs. $5.3 \pm 0.67 \mathrm{nmol} / \mathrm{mg}$ wet weight, $P<0.05$ ). 
A

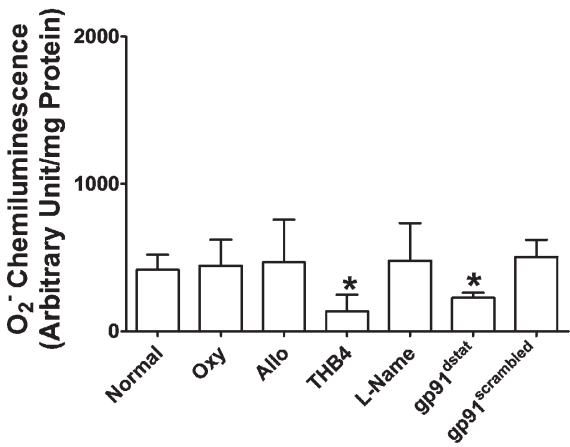

C

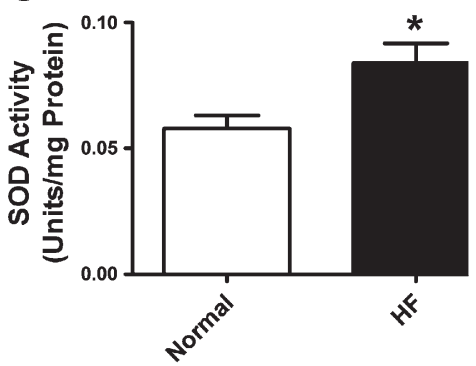

B

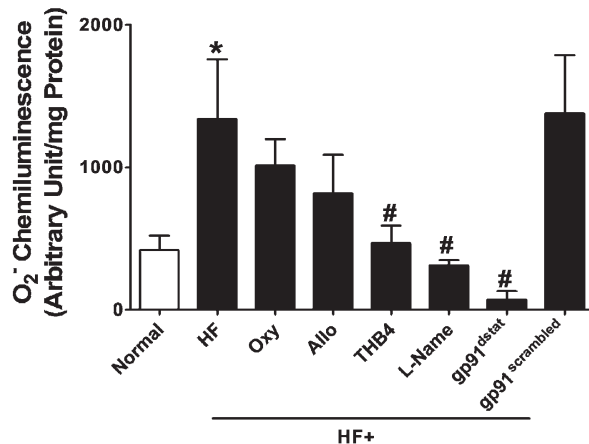

D

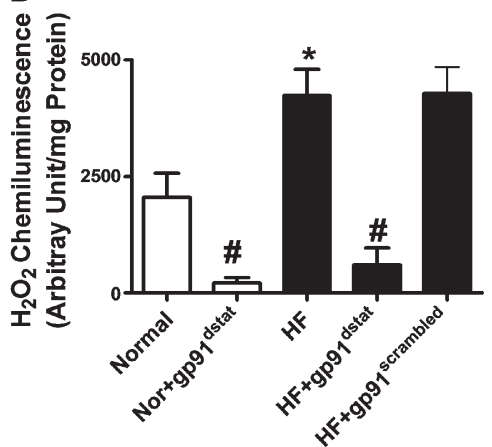

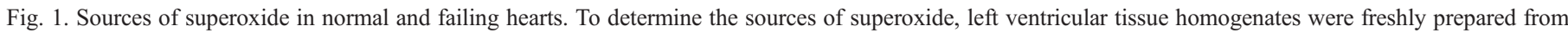

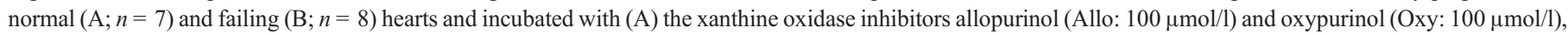

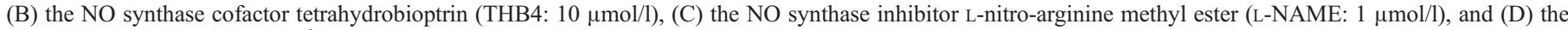

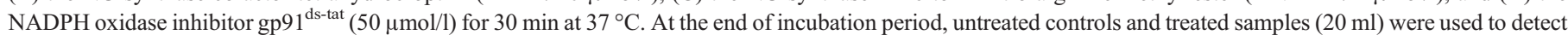

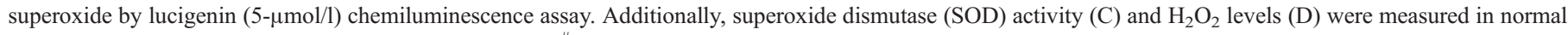
$(n=7)$ and failing $(n=8)$ hearts. ${ }^{*} P<0.05$ vs. normal. ${ }^{\#} P<0.05$ vs. heart failure.

\subsection{Glutathione concentration and glutathione reductase activity}

Concentration of reduced and oxidized glutathione and glutathione reductase activity is shown in Fig. 2. Oxidized glutathione was significantly elevated in heart failure compared to control (Fig. 2B). Ratio of GSSG-to-total glutathione was also significantly increased (Fig. 2C). Additionally, we found that the activity of glutathione reductase was significantly elevated in heart failure as compared to control (Fig. 2D).
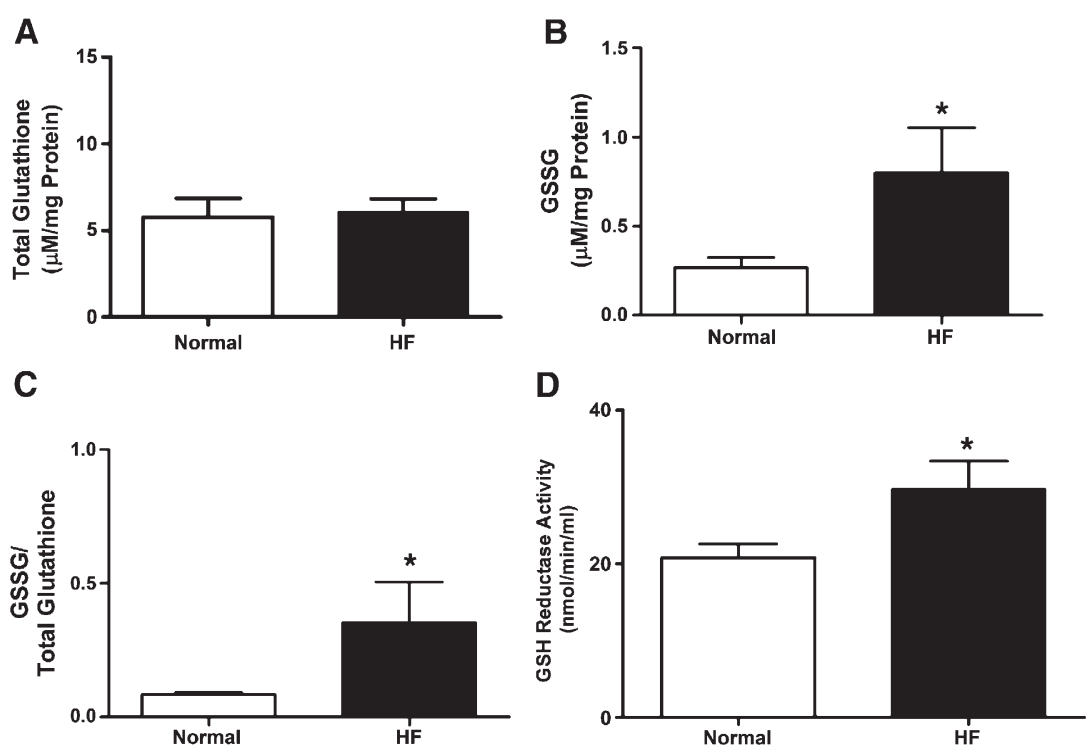

Fig. 2. Reduced and oxidized glutathione levels and glutathione reductase activity in the myocardium. Total glutathione (GSH + GSSG; A), oxidized glutathione (GSSG; B), GSSG-to-total glutathione ratio (C) levels and glutathione reductase activity were measured in normal $(n=7)$ and failing $(n=8)$ heart homogenates (D). $* P<0.05$ vs. normal. 


\subsection{NADPH concentration}

NADPH oxidase can utilize both NADPH and NADH as cosubstrates to generate $\mathrm{O}_{2}^{-}$. In failing heart tissue, NADH was approximately 46\% lower, while NADPH was approximately $100 \%$ higher (Fig. 3A). NADP ${ }^{+}$levels were unchanged in failing $(7.5 \pm 3.7 \mathrm{nmol} / \mathrm{g})$ vs. normal $(6.4 \pm 2.6 \mathrm{nmol} / \mathrm{g})$ hearts. Total $\mathrm{NADP}^{+}+\mathrm{NADPH}$ was increased in failing $(22.9 \pm$ $1.4 \mathrm{nmol} / \mathrm{g})$ compared to normal $(13.9 \pm 1.8 \mathrm{nmol} / \mathrm{g})$ hearts.

\subsection{Enhancement of $\mathrm{O}_{2}^{-}$production by $\mathrm{NADPH}$}

The effects of NADPH supplementation on $\mathrm{O}_{2}^{-}$production in failing heart tissue are shown in Fig. 3B. To determine the role of NADPH in regulating NADPH oxidase activity, normal and heart failure samples were incubated with NADPH (1$1000 \mu \mathrm{M})$ and $\mathrm{O}_{2}^{-}$generation was detected by lucigenin chemiluminescence assay. NADPH markedly stimulated $\mathrm{O}_{2}^{-}$ production in failing, but not in normal hearts, in a dosedependent manner (Fig. 3C). We also tested the effects of NADH supplementation on $\mathrm{O}_{2}^{-}$production. Surprisingly, we found that NADH $(100 \mu \mathrm{M})$ increased $\mathrm{O}_{2}^{-}$production in tissue from normal heart $(419 \pm 102$ vs. $3303 \pm 1305$ arbitrary units/ mg protein, $P<0.05)$, but not from failing heart $(1338 \pm 420 \mathrm{vs}$. $1759 \pm 1200$ arbitrary units/mg protein, N.S.).

\subsection{Gene and protein expression of Nox-2 and Nox-4}

Figs. 4A and B show that Nox-4 and Nox-2 gene expression was not significantly different in failing compared to normal hearts. Nox-4 protein expression was not significantly different, while Nox-2 protein expression was downregulated in failing compared to normal hearts (Figs. 5A and B). Immunoprecipitation of $\mathrm{p} 67^{\text {phox }}$ indicates that a complex of $\mathrm{p} 67^{\text {phox }}$ and Nox-2
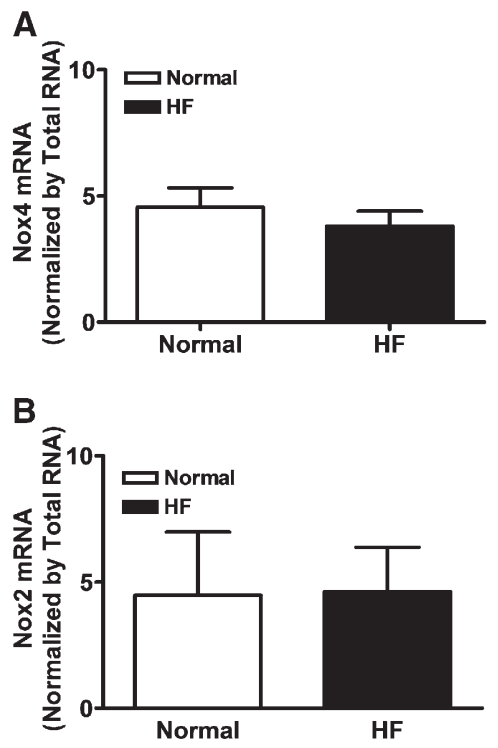

Fig. 4. qRT-PCR for NADPH oxidase, Nox-2 and Nox-4. Nox-4 (A) and Nox-2 (B) mRNA levels were measured by qRT-PCR.

is present in normal and failing hearts (Fig. 5C), with no significant difference between the two conditions. However, the relative fraction of Nox-2 bound to $\mathrm{p} 67^{\text {phox }}$, calculated as the ratio of the immunoprecipitated Nox-2-p67 $7^{\text {phox }}$ complex to Nox-2 prior to immunoprecipitation was increased in failing $(1.64 \pm 0.19)$ as compared to normal $(0.87 \pm 0.02)$ hearts, indicating activation of NADPH oxidase.

\subsection{Activity and expression of $G 6 P D$}

The pentose phosphate pathway is a major source of NADPH in most cells, including cardiac myocytes. Hence, we measured activity and expression of G6PD, the rate limiting

\section{A}
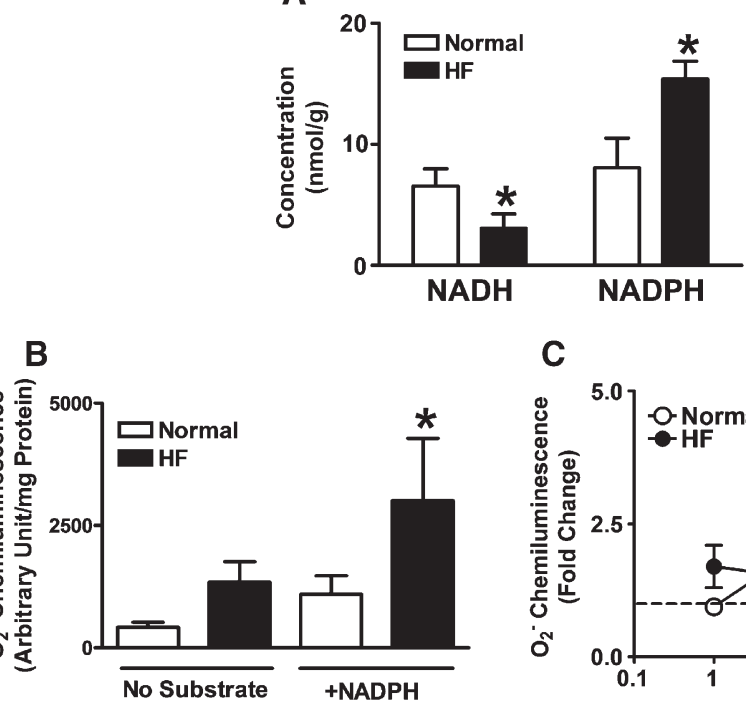

C

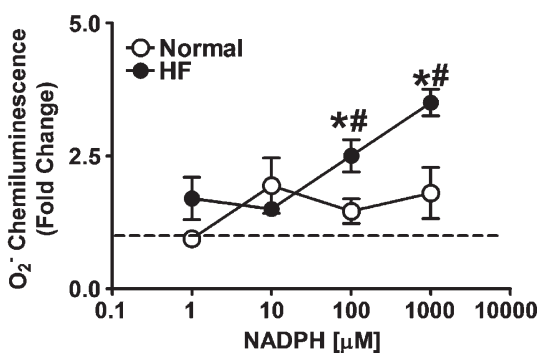

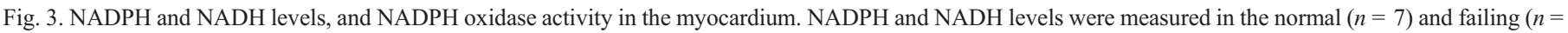

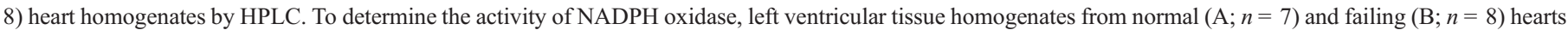

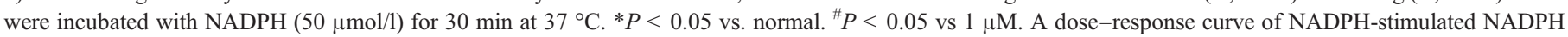
oxidase activity in myocardial homogenates from normal and failing hearts is shown in panel $\mathrm{C}$. 
A

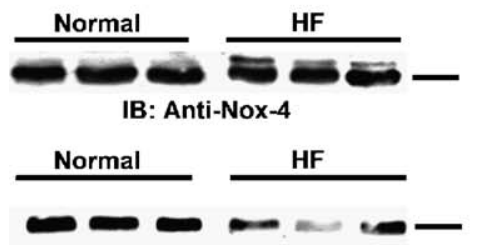

IB: Anti-Nox-2
B

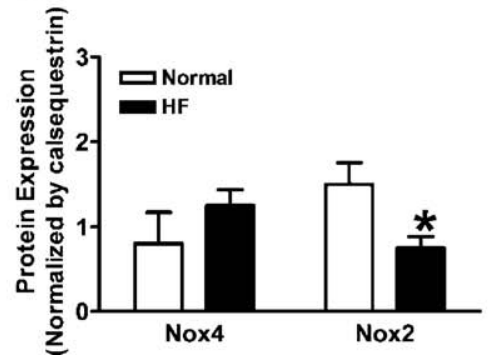

C

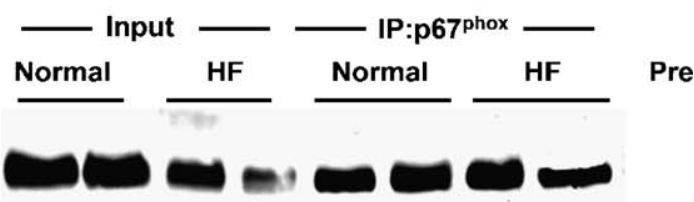

IB: Anti-Nox2

Fig. 5. Western blot analysis for NADPH oxidase, Nox-2 and Nox-4. Nox-4 and Nox-2 protein by Western blot. Representative immunoblot bands (A) and summary data (B) for Nox-4 and Nox-2 are shown. Lysates (1 mg of protein) prepared from myocardial tissue were immunoprecipitated with pre-immune serum (Pre) or polyclonal anti-p67 $7^{\text {phox }}$ antibody (IP) and then immunoblotted with monoclonal anti-Nox-2 antibody (C). All input lanes contained $35 \mu \mathrm{g}$ of total protein lysate obtained prior to immunoprecipitation. $n=7$ for normal and $n=8$ for heart failure. ${ }^{*} P<0.05$ vs. normal.

enzyme in the oxidative branch of the pentose phosphate pathway. G6PD activity was elevated by 1.5 -fold in failing compared to normal hearts (Fig. 6A). Consistent with this finding, the concentration 6-phosphogluconate, an intermediate product of the pentose phosphate pathway, was significantly elevated in heart failure (Fig. 6B). Furthermore, G6PD gene (Fig. 6C) and protein expression (Fig. 6D) were significantly higher in failing heart tissue.

\subsection{G6PD and $\mathrm{O}_{2}^{-}$production}

To investigate whether increased pentose phosphate pathway activity supplies NADPH to NADPH oxidase for sustained $\mathrm{O}_{2}^{-}$ generation in heart failure, we determined the effects of 6- aminonicotinamide, an irreversible inhibitor of G6PD, on $\mathrm{O}_{2}^{-}$ generation. As shown in Fig. 7, incubation of the heart homogenates with 6-aminonicotinamide did not affect $\mathrm{O}_{2}^{-}$ formation in normal myocardium, but almost completely abolished it in the failing myocardium. 6-Aminonicotinamide inhibited G6PD activity by $85.0 \pm 5.6 \%$ as compared to untreated control in normal and failing heart myocardial homogenates.

\section{Discussion}

Previous studies have provided substantial evidence that NADPH oxidase and uncoupled constitutive NOS are important sources of $\mathrm{O}_{2}^{-}$in the failing heart $[7,8,10,31]$. These enzymes
A

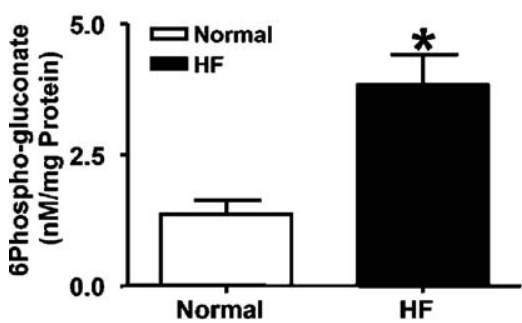

C

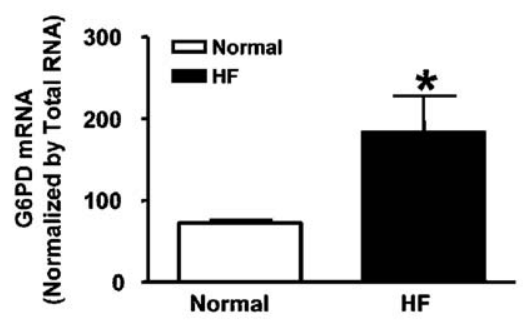

E
B
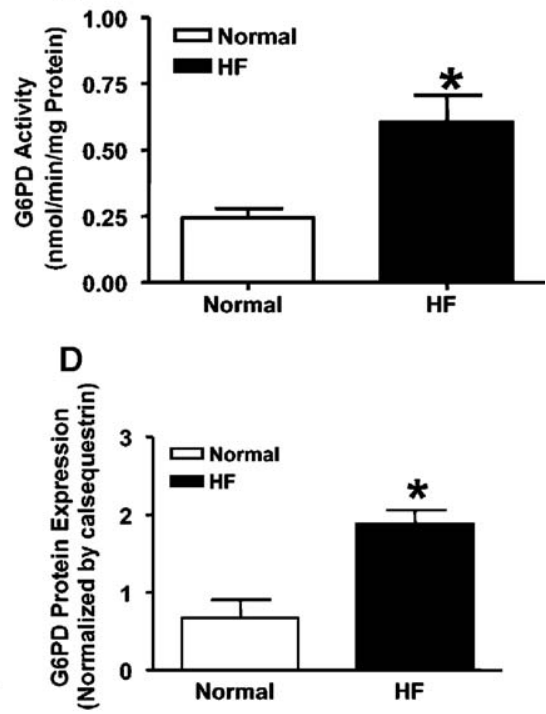

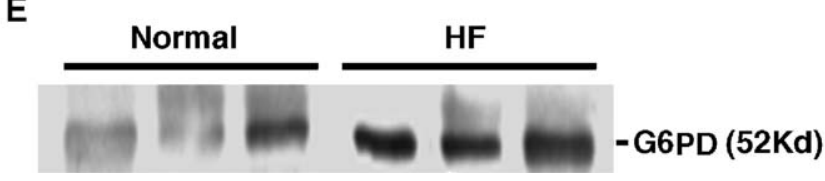

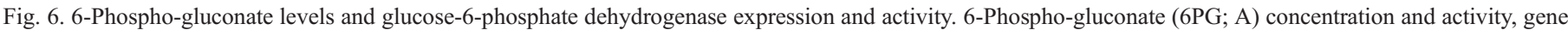

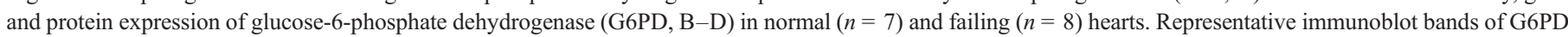
are also shown $(\mathrm{E}) .{ }^{*} P<0.05$ vs. normal. 


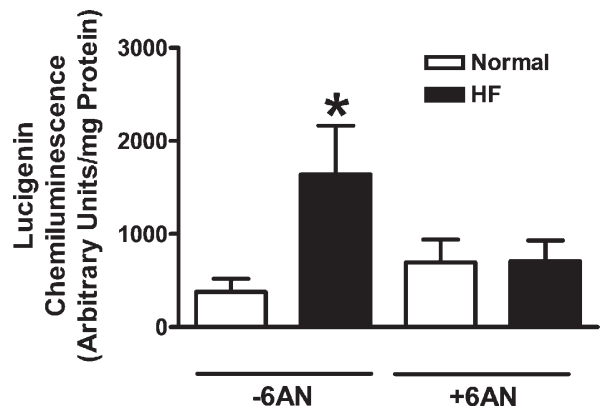

Fig. 7. Superoxide generation and glucose-6-phosphate dehydrogenase activity. Left ventricular tissue homogenates from normal and failing hearts were incubated for $30 \mathrm{~min}$ at $37{ }^{\circ} \mathrm{C}$ with or without 6-aminonicotinamide (6AN; $5 \mathrm{mmol} / \mathrm{l}$ ), an inhibitor of glucose-6-phosphate dehydrogenase (G6PD). $n=7$ for normal and $n=8$ for heart failure. ${ }^{*} P<0.05$ vs. normal.

can utilize cytosolic NADH and/or NADPH as electron donors and it remains to be established whether, under pathological conditions, they are driven by biochemical processes supplying reducing equivalents. The present findings indicate that heart failure causes upregulation and hyperactivity of myocardial G6PD, and strongly suggest that the pentose phosphate pathway enhances cytosolic NADPH availability, thus fueling $\mathrm{O}_{2}^{-}$ production by NADPH oxidase and uncoupled NO synthase. Since glucose utilization is higher in the failing heart [12], our study determined a novel mechanistic link between altered energy substrate metabolism, NADP reduction, and oxidative stress.

Cardiac oxidative stress plays a major role in the pathophysiology of heart failure. ROS cause diastolic dysfunction by impairing calcium-induced calcium release [32], decrease force generation without altering calcium sensitivity of myofilaments [33], and can activate metalloproteinases [34], thus triggering ventricular remodeling.

In accord with prior findings in human and experimental heart failure [7,8,31], we found elevated basal levels of $\mathrm{O}_{2}^{-}$ generation in myocardial tissue from dogs with pacing-induced heart failure, compared to normal hearts. The detection of increased oxidized glutathione and of lipoperoxidation end products further supports the presence of a state of oxidative stress in failing hearts. Therefore, the next step was to identify the enzymes responsible for $\mathrm{O}_{2}^{-}$generation. Under our experimental conditions, a major role was clearly played by NADPH oxidase, since its specific inhibitor gp9 ${ }^{\text {ds-tat }}$ almost completely abolished $\mathrm{O}_{2}^{-}$production in failing heart tissue. This finding is in evident accord with a previous study performed by Heymes et al. in homogenates of human failing heart [7]. Angiotensin II, noradrenaline, $\mathrm{TNF} \alpha$, and increased wall stress, all of which are known to play a role in the pathology of heart failure, activate NADPH oxidase. In fact, although we found that gene and protein expression of the NADPH subunit Nox-4 and Nox-2 was not increased, it is known that translocation of $\mathrm{p} 47^{\text {phox }}$ in cardiomyocytes from cytoplasm to plasma membrane in failing human hearts activates Nox-2 and $\mathrm{O}_{2}^{-}$ production [7]. We have directly assessed the activation state of the NADPH oxidase by determining complex of NADPH oxidase subunits. Unfortunately, we could not find an antibody binding to canine $\mathrm{p} 47^{\text {phox }}$, but we could detect the $\mathrm{p} 67^{\text {phox }}$-Nox2 interaction using a coimmunoprecipitation approach. We found a significant increase in the complex between Nox-2 and p $67^{\text {phox }}$ in normal vs. failing heart. This finding supports a higher activation state of NADPH oxidase in the failing heart, which has been already documented by other investigators $[7,8]$. On the other hand, the NO synthase cofactor tetrahydrobiopterin or the competitive inhibitor L-NAME reduced $\mathrm{O}_{2}^{-}$ levels by approximately $65 \%$ and $77 \%$, respectively, which indirectly indicated the presence of uncoupled NO synthase generating $\mathrm{O}_{2}^{-}$in the failing heart. The mechanisms of NOS uncoupling could be very complex in a multifactorial disease such as heart failure and not necessarily limited to tetrahydrobiopterin availability. For instance, it has been shown that the association between heat shock protein 90 and eNOS limits eNOS uncoupling even in normal hearts [35] and this mechanism could be altered in the failing heart. Although we cannot exclude that tetrahydrobiopetrin itself scavenged part of $\mathrm{O}_{2}^{-}$in our tissue preparations, an important role for uncoupled NOS is supported by the effect of L-NAME. Finally, $\mathrm{O}_{2}^{-}$ generation was reduced, albeit not significantly, by the xanthine oxidase inhibitors allopurinol and oxypurinol. Although our assay was not designed to precisely quantify the relative contribution of different $\mathrm{O}_{2}^{-}$generating enzymes, these data indicate that NADPH oxidase and uncoupled NOS played an important role. Interestingly, the addition of NADPH further enhanced $\mathrm{O}_{2}^{-}$production in a dose-dependent manner, suggesting that NADPH oxidase activity uses NADPH as an electron donor in the failing heart. This has important implications when we consider that endogenous NADPH concentration was increased by almost two-fold in heart failure.

What is the molecular basis for such a high level of NADPH in failing hearts? Previous studies from our group and others showed that pentose phosphate pathway-derived NADPH is a major cosubstrate for NADPH oxidase $[16,17]$. Since glucose utilization is higher in the failing heart $[12,13]$, we hypothesized that an increased amount of this energy substrate could be channeled through the oxidative branch of the pentose phosphate pathway, which is a major source of NADPH in most cell types, including cardiac myocytes [36-38]. Compared to control, expression and activity G6PD were found indeed markedly elevated in the failing heart. This was consistent with a more than doubled concentration of 6-phosphogluconate, the product of the second reaction catalyzed along the pentose phosphate pathway. G6PD expression and activity can be stimulated by a large number of factors, only partially known, while heart failure is characterized by an enormous number of biochemical/molecular alterations. Although our data do not provide mechanisms for G6PD upregulation, it should be considered that elevated levels of $\mathrm{O}_{2}^{-}$and $\mathrm{H}_{2} \mathrm{O}_{2}$, per se, could directly induce G6PD expression [39], and increased levels of GSSG could activate G6PD [40].

When G6PD was inhibited, $\mathrm{O}_{2}^{-}$dropped to levels found in normal hearts, indicating that the continuous supply of NADPH from the pentose phosphate pathway was necessary to drive $\mathrm{O}_{2}^{-}$ generation. We cannot exclude an important contribution of mitochondrial respiratory chain complexes or other enzymes to 
the generation of $\mathrm{O}_{2}^{-}$in vivo; however, taken together, our data provide compelling evidence that failing heart tissue maintains elevated levels of NADPH and has the molecular machinery capable of enhancing glucose flux through the pentose phosphate pathway, thus supplying large amounts of NADPH that drive $\mathrm{O}_{2}^{-}$production. Interestingly, the increased availability of NADPH in failing hearts appeared to have a more dominant effect on promoting superoxide production compared to its antioxidant metabolic effect of maintaining high levels of reduced glutathione. A possible explanation is that, while in normal hearts G6PD-derived NADPH is critical to preserve cytosolic antioxidant redox systems such as GSH, $[37,38]$ in the presence of pathologically enhanced superoxide-generating systems sharing the same type of electron donor, the NADPH oxidase has a greater affinity for the available electron donor. Consistent with this interpretation, other authors have recently reported that, in a pathological condition induced by angiotensin infusion, G6PD deficiency limits the deleterious effects of vascular superoxide production possibly by reducing the availability of the substrate for NADPH oxidase [16].

In severe heart failure, cardiac oxidation of free fatty acid is impaired, leading to augmented uptake and oxidation of the alternative substrate glucose. However, other authors and us previously found molecular alterations suggestive of a depressed, rather than increased, glycolytic pathway $[14,15]$. This is part of the global mitochondrial impairment that characterizes heart failure [11]. It is possible, therefore, that a larger fraction of glucose enters the upregulated pentose phosphate pathway.

In conclusion, our study provides evidence for elevated NADPH in the failing heart due to G6PD upregulation. This biochemical alteration drives superoxide production by NADPH oxidase and uncoupled NO synthase. Thus, the flux of glucose metabolism through the pentose phosphate pathway may be playing an important role in fueling the oxidative stress seen in heart failure.

\section{Acknowledgments}

This study was supported by an AHA Scientist Development grant (S.A. Gupte), and by HL-31069 and HL-66331 (MSW), and P01 HL-74237 (F.A. Recchia). Authors would like to thank Dr. Pagano, Henry Ford Hospital, Detroit, MI, for kindly providing NADPH oxidase inhibitor gp91 $1^{d s-t a t}$.

\section{References}

[1] Li JM, Shah AM. Endothelial cell superoxide generation: regulation and relevance for cardiovascular pathophysiology. Am J Physiol, Regul Integr Comp Physiol 2004;287:R1014-30.

[2] Dhalla NS, Temsah RM, Netticadan T. Role of oxidative stress in cardiovascular diseases. J Hypertens 2000;18:655-73.

[3] Ballinger SW. Mitochondrial dysfunction in cardiovascular disease. Free Radic Biol Med 2005;38:1278-95.

[4] Berry CE, Hare JM. Xanthine oxidoreductase and cardiovascular disease: molecular mechanisms and pathophysiological implications. J Physiol 2004;555:589-606.

[5] Griendling KK, Sorescu D, Ushio-Fukai M. NAD(P)H oxidase: role in cardiovascular biology and disease. Circ Res 2000;86:494-501.

[6] Cappola TP, Kass DA, Nelson GS, Berger RD, Rosas GO, Kobeissi ZA, et al. Allopurinol improves myocardial efficiency in patients with idiopathic dilated cardiomyopathy. Circulation 2001;104:2407-11.

[7] Heymes C, Bendall JK, Ratajczak P, Cave AC, Samuel JL, Hasenfuss G, et al. Increased myocardial NADPH oxidase activity in human heart failure. J Am Coll Cardiol 2003;41:2164-71.

[8] Maack C, Kartes T, Kilter H, Schafers HJ, Nickenig G, Bohm M, et al. Oxygen free radical release in human failing myocardium is associated with increased activity of rac1-GTPase and represents a target for statin treatment. Circulation 2003;108:1567-74.

[9] Wolin MS, Gupte SA, Oeckler RA. Superoxide in the vascular system. J Vasc Res 2002;39:191-207.

[10] Dixon LJ, Morgan DR, Hughes SM, McGrath LT, El-Sherbeeny NA, Plumb RD, et al. Functional consequences of endothelial nitric oxide synthase uncoupling in congestive cardiac failure. Circulation 2003;107: 1725-8.

[11] Stanley WC, Recchia FA, Lopaschuk GD. Myocardial substrate metabolism in the normal and failing heart. Physiol Rev 2005;85:1093-129.

[12] Osorio JC, Stanley WC, Linke A, Castellari M, Diep QN, Panchal AR, et al. Impaired myocardial fatty acid oxidation and reduced protein expression of retinoid $\mathrm{X}$ receptor-alpha in pacing-induced heart failure. Circulation 2002;106:606-12.

[13] Davila-Roman VG, Vedala G, Herrero P, de las Fuentes L, Rogers JG, Kelly DP, et al. Altered myocardial fatty acid and glucose metabolism in idiopathic dilated cardiomyopathy. J Am Coll Cardiol 2002;40:271-7.

[14] Lei B, Lionetti V, Young ME, Chandler MP, d'Agostino C, Kang E, et al. Paradoxical downregulation of the glucose oxidation pathway despite enhanced flux in severe heart failure. J Mol Cell Cardiol 2004;36:567-76.

[15] Razeghi P, Young ME, Alcorn JL, Moravec CS, Frazier OH, Taegtmeyer H. Metabolic gene expression in fetal and failing human heart. Circulation 2001;104:2923-31.

[16] Matsui R, Xu S, Maitland KA, Hayes A, Leopold JA, Handy DE, et al. Glucose-6 phosphate dehydrogenase deficiency decreases the vascular response to angiotensin II. Circulation 2005;112:257-63.

[17] Gupte SA, Kaminski PM, Floyd B, Agarwal R, Ali N, Ahmad M, et al. Cytosolic NADPH may regulate differences in basal Nox oxidase-derived superoxide generation in bovine coronary and pulmonary arteries. Am J Physiol, Heart Circ Physiol 2005;288:H13-21.

[18] Lionetti V, Linke A, Chandler MP, Young ME, Penn MS, Gupte S, et al. Carnitine palmitoyl transferase-I inhibition prevents ventricular remodeling and delays decompensation in pacing-induced heart failure. Cardiovasc Res 2005;66:454-61.

[19] Mohazzab KM, Wolin MS. Sites of superoxide anion production detected by lucigenin in calf pulmonary artery smooth muscle. Am J Physiol 1994;267:L815-22.

[20] Ungvari Z, Csiszar A, Edwards JG, Kaminski PM, Wolin MS, Kaley G, et al. Increased superoxide production in coronary arteries in hyperhomocysteinemia: role of tumor necrosis factor-alpha, $\mathrm{NAD}(\mathrm{P}) \mathrm{H}$ oxidase, and inducible nitric oxide synthase. Arterioscler Thromb Vasc Biol 2003;23:418-24.

[21] Kinugawa S, Huang H, Wang Z, Kaminski PM, Wolin MS, Hintze TH. A defect of neuronal nitric oxide synthase increases xanthine oxidase-derived superoxide anion and attenuates the control of myocardial oxygen consumption by nitric oxide derived from endothelial nitric oxide synthase. Circ Res 2005;96:355-62.

[22] Chalupsky K, Cai H. Endothelial dihydrofolate reductase: critical for nitric oxide bioavailability and role in angiotensin II uncoupling of endothelial nitric oxide synthase. Proc Natl Acad Sci U S A 2005;102:9056-61.

[23] Rey FE, Cifuentes ME, Kiarash A, Quinn MT, Pagano PJ. Novel competitive inhibitor of $\mathrm{NAD}(\mathrm{P}) \mathrm{H}$ oxidase assembly attenuates vascular $\mathrm{O}$ (2)(-) and systolic blood pressure in mice. Circ Res 2001;89:408-14.

[24] Kohler E, Barrach H, Neubert D. Inhibition of NADP dependent oxidoreductases by the 6-aminonicotinamide analogue of NADP. FEBS Lett 1970;6:225-8.

[25] Mohazzab-H KM, Agarwal R, Wolin MS. Influence of glutathione peroxidase on coronary artery responses to alterations in $\mathrm{PO}_{2}$ and $\mathrm{H}_{2} \mathrm{O}_{2}$. Am J Physiol 1999;276:H235-41.

[26] Radi R, Cosgrove TP, Beckman JS, Freeman BA. Peroxynitrite-induced luminol chemiluminescence. J Biochem 1993;290(Pt 1):51-7. 
[27] Gupte SA, Arshad M, Viola S, Kaminski PM, Ungvari Z, Rabbani G, et al. Pentose phosphate pathway coordinates multiple redox-controlled relaxing mechanisms in bovine coronary arteries. Am J Physiol, Heart Circ Physiol 2003;285:H2316-26.

[28] Blum J, Fridovich I. Superoxide, hydrogen peroxide, and oxygen toxicity in two free-living nematode species. Arch Biochem Biophys 1983;222: $35-43$.

[29] Kauffman FC, Brown JG, Passonneau JV, Lowry OH. Effects of changes in brain metabolism on levels of pentose phosphate pathway intermediates. J Biol Chem 1969;244:3647-53.

[30] Gupte RS, Weng Y, Liu L, Lee MY. The second subunit of the replication factor $\mathrm{C}$ complex (RFC40) and the regulatory subunit (RIalpha) of protein kinase A form a protein complex promoting cell survival. Cell Cycle 2005;4:323-9.

[31] Mollnau H, Oelze M, August M, Wendt M, Daiber A, Schulz E, et al. Mechanisms of increased vascular superoxide production in an experimental model of idiopathic dilated cardiomyopathy. Arterioscler Thromb Vasc Biol 2005.

[32] Gao WD, Liu Y, Marban E. Selective effects of oxygen free radicals on excitation-contraction coupling in ventricular muscle. Implications for the mechanism of stunned myocardium. Circulation 1996;94:2597-604.

[33] MacFarlane NG, Miller DJ. Depression of peak force without altering calcium sensitivity by the superoxide anion in chemically skinned cardiac muscle of rat. Circ Res 1992;70:1217-24.
[34] Siwik DA, Pagano PJ, Colucci WS. Oxidative stress regulates collagen synthesis and matrix metalloproteinase activity in cardiac fibroblasts. Am J Physiol, Cell Physiol 2001;280:C53-60.

[35] Shi Y, Baker JE, Zhang C, Tweddell JS, Su J, Pritchard Jr KA. Chronic hypoxia increases endothelial nitric oxide synthase generation of nitric oxide by increasing heat shock protein 90 association and serine phosphorylation. Circ Res 2002;91:300-6.

[36] Gupte SA, Tateyama M, Okada T, Oka M, Ochi R. Epiandrosterone, a metabolite of testosterone precursor, blocks L-type calcium channels of ventricular myocytes and inhibits myocardial contractility. J Mol Cell Cardiol 2002;34:679-88.

[37] Jain M, Brenner DA, Cui L, Lim CC, Wang B, Pimentel DR, et al. Glucose-6-phosphate dehydrogenase modulates cytosolic redox status and contractile phenotype in adult cardiomyocytes. Circ Res 2003;93: e9-16.

[38] Jain M, Cui L, Brenner DA, Wang B, Handy DE, Leopold JA, et al. Increased myocardial dysfunction after ischemia-reperfusion in mice lacking glucose-6-phosphate dehydrogenase. Circulation 2004;109: 898-903.

[39] Kletzien RF, Harris PK, Foellmi LA. Glucose-6-phosphate dehydrogenase: a "housekeeping" enzyme subject to tissue-specific regulation by hormones, nutrients, and oxidant stress. FASEB J 1994;8:174-81.

[40] Eggleston LV, Krebs HA. Regulation of the pentose phosphate cycle. Biochem J 1974;138:425-35. 